\title{
Strong and positive association of Endothelin-1 with AGEs in PCOS: A causal relationship or a bystander?
}

\author{
Christakou Charikleia ${ }^{1}$, Economou Frangiskos ${ }^{1}$, Livadas Sarantis ${ }^{1}$, Piperi Christina ${ }^{2}$, \\ Adamopoulos Christos ${ }^{2}$, Marinakis Evangelos ${ }^{1}$, Diamanti-Kandarakis Evanthia ${ }^{1}$
}

${ }^{1}$ Endocrine Unit, Third Department of Internal Medicine, Medical School, National and Kapodistrian University of Athens, ${ }^{2}$ Department of Biological Chemistry, University of Athens Medical School, Athens, Greece

\begin{abstract}
OBJECTIVE: Advanced glycation end products (AGEs) activate the intracellular Nuclear Factor- $\varkappa B$ pathway in endothelial cells, leading to production of endothelin-1 (ET-1), a peptide which causes endothelial dysfunction. The aim of the present study was to assess ET-1 and AGEs levels in women with polycystic ovary syndrome (PCOS) and controls and to investigate any potential relationship between them. DESIGN: Metabolic and hormonal data from 75 women with PCOS and 25 controls, matched for age and BMI were analyzed and correlated to AGEs and ET-1 levels. RESULTS: Serum levels of ET-1 (1.55 $\pm 0.13 \mathrm{vs.} 0.37 \pm 0.10 \mathrm{pmol} / \mathrm{l}, \mathrm{p:0.003})$ and AGEs $(8.34 \pm 1,81$ vs. $5.77 \pm 0.78 \mathrm{U} / \mathrm{ml}, \mathrm{p}: 0.002)$ were significantly higher in the PCOS group. ET-1 was correlated with AGES ( $r: 0.54, p<0.001)$, Testosterone $(r: 0.38, p<0.001), \Delta$ A4 $(r$ : $0.41, p<0.001)$ and FAI (r: $0.21, p<0.05)$. However, multiple linear regression analysis in the total study population showed that ET-1 was positively associated only with AGES ( $\beta$ : 0.22, p<0.001). CONCLUSIONS: ET-1 levels were positively and strongly associated with AGEs in both PCOS women and controls, suggesting that the detrimental effect of AGEs on endothelial cells may involve increased ET-1 production.
\end{abstract}

Key Words: Advanced glycation end products, Endothelin-1, PCOS, Androgens, Insulin resistance

\section{INTRODUCTION}

Advanced glycation end products (AGEs), the products of non-enzymatic glycation and oxidation of proteins and lipids, have been associated with insulin resistance and cardiovascular aberrations not

\footnotetext{
Address for correspondence:

Evanthia Diamanti-Kandarakis, Endocrine Unit, $3^{\text {rd }}$ Department of Internal Medicine, Medical School, National and Kapodistrian University of Athens, Athens, Greece, e-mail: e.diamanti.kandarakis@gmail.com Received 05-07-11, Revised 27-08-11, Accepted 10-09-11
}

only in diabetic but also in non-diabetic individuals. ${ }^{1-5}$ Non-diabetic women with polycystic ovarian syndrome (PCOS), which is the commonest female endocrinopathy, display increased serum AGEs levels. This finding appears to characterize the syndrome, even in the absence of obesity and insulin resistance. ${ }^{6,7}$ Increased AGEs levels may play an independent role in the pathophysiology of endothelial dysfunction and hence cardiovascular disease in PCOS. ${ }^{8-14}$ Specifically, AGEs activate nuclear factor- $\varkappa \mathrm{B}$ (NF$\varkappa \mathrm{B})$, a transcription factor which upregulates gene 
expression of molecules involved in vascular injury and endothelial dysfunction, including adhesion molecules and endothelin-1 (ET-1) $\cdot{ }^{15}$ ET- 1 , which is an endothelial-derived vasoconstrictor peptide and a major biochemical marker of endothelial dysfunction, has been found at increased levels in women with PCOS..$^{10-14}$

Thus, in women with PCOS endothelial dysfunction may reflect the cardiovascular impact of increased AGEs levels. However, the potential specific role of AGEs in endothelial dysfunction associated with PCOS remains speculative. To gain insight into this issue, the present study addresses the association of serum AGEs with serum ET-1 levels in women with PCOS. To exclude any confounding effect of obesity and insulin resistance on endothelial dysfunction, the study population included young, lean, non-insulin resistant women with PCOS and control women with comparable age and BMI.

\section{SUBJECTS AND METHODS}

The study population was composed of 75 women with PCOS and 25 controls of Caucasian origin of comparable age, matched for body mass index (BMI) and waist-to-hip ratio (WHR). All participants were recruited from the PCOS-Endocrine Unit of Evgenidion University hospital in Athens. The diagnosis of PCOS was established according to the National Institute of Health (NIH) criteria, which require the combination of chronic anovulation and clinical or biochemical hyperandrogenism. ${ }^{16}$

Control women (the control group was the same which was included in a previous study published in 2001) $)^{10}$ had regular ovulation - confirmed by midluteal serum progesterone levels above $5 \mathrm{ng} / \mathrm{ml}$ on two consecutive cycles - and no hyperandrogenemia (serum total testosterone levels below 60ng/dl). Ovarian morphology was ultrasonographically assessed as normal in the control group.

All subjects were selected among non-smokers and none had been taking any medication known to affect lipid, carbohydrate or sex hormone metabolism for at least 6 months before the study. Exclusion criteria also included intense physical activity, hypothyroidism, hyperprolactinemia, Cushing's syndrome, metabolic (diabetes mellitus) or cardiovascular (hypertension, ischemic heart disease) disorders, or other concurrent medical illness (kidney, liver disease). A Synachten test (Synacthen $0.25 \mathrm{mg} / \mathrm{ml}$, Novartis Pharma SA, RueilMalmaison, France) was performed in all patients to exclude non-classic congenital adrenal hyperplasia.

Anthropometric parameters were measured in all participants at baseline. Subjects were weighed in light clothing without shoes. Height was measured to the nearest $0.1 \mathrm{~cm}$ using a wall-mounted stadiometer. BMI was calculated from body weight and height by the standard formula: $\mathrm{BMI}=($ weight in $\mathrm{kg} /$ height in $\mathrm{m}^{2}$ ). Waist circumference (WC) was estimated as the smallest circumference at the level of the umbilicus. Hip circumference was estimated as the widest circumference at the level of the buttocks. Waist-to-hip ratio (WHR) was calculated as a marker of body fat distribution, according to the standard formula: $\mathrm{WHR}=$ waist circumference $(\mathrm{cm})$ / hip circumference $(\mathrm{cm})$.

Informed written consent was obtained from all women and the study was approved by the local Institutional Review Committee.

\section{Laboratory Assays}

Patients and controls were studied during the early follicular phase of the menstrual cycle (3-7 days after the onset of spontaneous menstrual bleeding). In the amenorrhoeic women, recent ovulation was excluded by progesterone measurement $(<5 \mathrm{ng} / \mathrm{ml})$. All blood samples were obtained between 08:00 and 09:00 $\mathrm{h}$ in the morning after overnight fasting.

Plasma glucose was determined by the glucose oxidase method (glucose analyzer, Beckman Coulter, Inc., Palo Alto, CA). Blood samples were centrifuged immediately, and serum was stored at $-80 \mathrm{C}$ until assayed for insulin (Ins), total testosterone (Testo), sex hormone-binding globulin (SHBG), androstenedione $(\triangle 4 \mathrm{~A})$ and dehydroepiandrosterone sulphate (DHEA-S). Serum insulin levels were measured using the RIA INSULIN-CT kits (CIS-Bio International, Gif-sur-Yvette, France). The assays employed for sex steroid levels, AGEs and ET-1 measurements have been reported elsewhere. ${ }^{6,710}$ The free androgen index (FAI) was calculated by the standard formula: $\mathrm{FAI}=100 \times$ Total Testo $(\mathrm{nmol} / \mathrm{l}) / \mathrm{SHBG}(\mathrm{nmol} / \mathrm{l})$. Homeostasis model assessment for insulin resistance 
(HOMA-IR) was calculated using the standard formula: fasting glucose $(\mathrm{mmol} / \mathrm{l}) /$ fasting insulin $(\mathrm{mIU} /$ $\mathrm{ml}) / 22.5 \cdot{ }^{17}$

\section{Statistical analysis}

All continuous variables showed normal distribution as documented by the use of the KolmogorovSmirnov test. Data are presented as mean values \pm standard errors (SE). The two-tailed unpaired t-test was used to evaluate the differences in normally distributed variables between groups. The Pearson correlation coefficient was applied to assess the potential correlation of ET-1 with AGEs, BMI, metabolic and hormonal variables. Multiple regression analysis was used to examine the relationship of ET-1 with AGES and all other variables in the total study population. All tests were two-sided and statistical significance was set at $p<0.05$. All analyses were carried out using the statistical package SPSS vs 17.00 (Statistical Package for the Social Sciences, SPSS Inc., Chicago, Ill., USA).

\section{RESULTS}

Women with PCOS and controls were lean and did not differ significantly in age $(27.02 \pm 0.9 \mathrm{vs} 25.05 \pm 0.5$ years, $\mathrm{p}=0.08)$, BMI $\left(22.15 \pm 0.2\right.$ vs $22.35 \pm 0.3 \mathrm{~kg} / \mathrm{m}^{2}$, $\mathrm{p}=0.61)$ and WHR $(0.74 \pm 0.006$ vs $0.74 \pm 0.01, \mathrm{p}=0.77)$ (Table 1). Serum AGEs (8.34 \pm 0.2 vs $5.77 \pm 0.1 \mathrm{IU} / \mathrm{ml}$, p:0.003) and serum ET-1 levels (1.55 \pm 0.1 vs $0.37 \pm 0.1$ $\mathrm{pmol} / \mathrm{l}, \mathrm{p}: 0.002)$ were significantly higher in PCOS women than in controls. Pertinent data of the studied women are presented in Table 1. Partial correlation analysis in the total study population showed that ET-1 was significantly and positively correlated with serum AGES (r:0.54, p<0.001) (Figure 1), testosterone $(\mathrm{r}: 0.38, \mathrm{p}<0.001), \Delta 4 \mathrm{~A}(\mathrm{r}: 0.41, \mathrm{p}<0.001)$ and FAI ( $\mathrm{r}: 0.21, \mathrm{p}: 0.02)$. However, multiple linear regression analysis in the total study population showed that only serum AGEs were significantly correlated with serum ET-1 ( $\beta: 0.22, p<0.001)$, independently of testosterone, $\triangle 4 \mathrm{~A}$ and FAI. Furthermore, in the PCOS group ET-1 levels were positively related only with AGEs levels (r:0.385, p:0.02).

\section{DISCUSSION}

The present study shows for the first time that
Table 1. Clinical, hormonal and metabolic parameters in PCOS patients and controls

\begin{tabular}{lccc}
\hline & PCOS $(\mathbf{n = 7 5})$ & Controls $(\mathbf{n = 2 5})$ & P \\
\hline Age (years) & $25.05 \pm 0.5$ & $27.02 \pm 0.9$ & 0.08 \\
BMI (kg/m2) & $22.15 \pm 0.2$ & $22.35 \pm 0.3$ & 0.61 \\
WHR & $0.74 \pm 0.06$ & $0.74 \pm 0.01$ & 0.77 \\
AGEs (U/ml) & $8.34 \pm 0.2$ & $5.77 \pm 0.1$ & 0.002 \\
ET-1 (pmol/l) & $1.55 \pm 0.1$ & $0.37 \pm 0.1$ & 0.003 \\
Testo (ng/dl) & $84.75 \pm 2.7$ & $40.14 \pm 2.3$ & 0.001 \\
SHBG (nmol/l) & $44.55 \pm 2.1$ & $69.84 \pm 4.3$ & 0.007 \\
FAI & $6.39 \pm 0.8$ & $0.76 \pm 0.1$ & $<0.001$ \\
$\Delta 4 A(\mathrm{ng} / \mathrm{ml})$ & $3.09 \pm 0.12$ & $1.61 \pm 0.07$ & 0.006 \\
DHEAS (ng/dl) & $2979 \pm 143$ & $1907 \pm 157$ & 0.007 \\
Glucose (mg/dl) & $95.48 \pm 1.51$ & $93.04 \pm 2.62$ & 0.42 \\
Insulin (IU/ml) & $8.28 \pm 0.56$ & $6.90 \pm 0.69$ & 0.19 \\
HOMA-IR & $1.9 \pm 0.14$ & $1.5 \pm 0.18$ & 0.20 \\
\hline
\end{tabular}

Data are expressed as mean values \pm standard errors. $\mathrm{P}<0.05$ indicates significant difference between patients and controls.

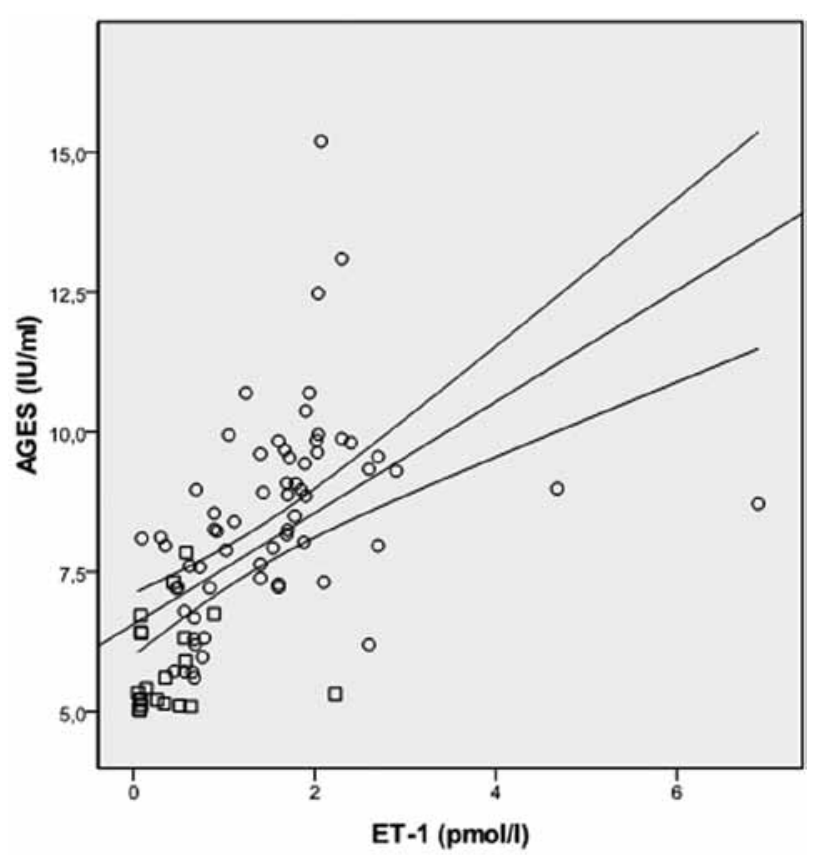

Figure 1. Correlation of serum AGEs with serum ET-1 in the study population (Pearson analysis, r:0.54, p<0.001). Squares denote controls and cycles denote women with PCOS.

increased plasma ET-1 levels are positively associated with increased serum AGEs levels in young, lean, non-insulin resistant PCOS women (Figure 1). This association is independent of BMI, insulin 
resistance and hyperandrogenemia and suggests a potential direct interaction between AGEs and the vasoconstrictor peptide, ET-1, in the pathophysiologic context of PCOS. The concomitant elevation of these two atherogenic molecules (AGEs, ET-1) and their direct correlation, demonstrated in young, lean, non-insulin resistant PCOS patients, likely contributes to an increased risk for cardiovascular disease in this group. ${ }^{9}$

AGEs constitute a heterogeneous group of molecules, either endogenously formed by the non-enzymatic glycation of proteins, lipids and nucleic acids, or exogenously derived mainly from diet. ${ }^{2,18}$ AGEs modify vascular collagen by cross-linking ${ }^{19}$ and increase oxidation of low-density lipoprotein. ${ }^{20}$ Additionally, AGEs act through their own receptor (Receptor for AGEs, RAGE) to upregulate the expression of adhesion molecules ${ }^{21,22}$ and inflammatory cytokines. ${ }^{23}$ All these actions may account for the detrimental impact of AGEs on the cardiovascular system.

In the clinical setting, carboxymethyl-lysine(CML), the dominant circulating AGE and the best characterized of all the AGEs, was shown to predict cardiovascular disease mortality in older communitydwelling women. ${ }^{5}$ These findings may have long-term cardiovascular implications for women with PCOS, since the increase of serum AGEs in hyperandrogenic women or PCOS women starts from a young age and persists after menopause. ${ }^{7,24}$ The long-lasting exposure to AGEs excess may contribute to the increased risk for cardiovascular disease and cardiovascular incidents reported in postmenopausal women with PCOS features. ${ }^{8}$

Our findings point to a mechanism whereby increased serum AGEs could possibly contribute to endothelial dysfunction and thereby precipitate cardiovascular aberrations in women with PCOS. AGEs may contribute to elevated plasma ET-1 levels through direct or indirect pathways. More specifically, AGEs are liable to directly amplify NF-kB-dependent ET-1 gene expression, as shown by in vitro experiments. ${ }^{25}$ Furthermore, AGEs induce generation of reactive oxygen species and activation of NADPH oxidase is a major step in this process. ${ }^{26}$ The resultant oxidative stress may perpetuate a bidirectional relationship between AGEs and ET-1. This mechanism appears to be relevant to the pathophysiology of PCOS, since women with the syndrome display increased levels of oxidative stress. ${ }^{27-29}$ In addition, ET-1 has been shown to enhance oxidative stress, ${ }^{30}$ thus possibly creating a vicious cycle between ET-1, AGEs, oxidants and PCOS.

Since insulin resistance is a major driver of endothelial dysfunction ${ }^{31}$ and AGEs directly contribute to insulin resistance,$^{32}$ this could be a mechanism partly accounting for the reported association between ET-1 and AGEs in our study. However, in the present study all subjects were non-insulin resistant, as assessed by HOMA-IR, and did not differ in fasting insulin and glucose levels. Therefore, the confounding role of insulin resistance can be excluded, a fact that should be considered as an important strength of our study.

Another plausible mediator of the association between ET-1 and AGEs is hyperandrogenemia. The present study confirms previous data showing that serum testosterone levels are directly correlated with serum ET-1 levels in women with PCOS. ${ }^{10}$ The mechanism via which androgen excess may be linked with higher ET-1 levels remains unknown, although males display higher ET-1 levels and greater ET1-mediated vasoconstrictor response in comparison with females. ${ }^{33,34}$ Two previous studies have shown a positive correlation of serum testosterone, with ET-1 in one and with serum AGEs in the other. ${ }^{8,10}$ Thus, increased testosterone levels could be the common denominator in the observed correlation between AGEs and ET-1. However, the correlation of ET-1 with testosterone was not confirmed by multiple regression analysis in the present study. Most strikingly, multiple regression analysis showed an independent positive correlation of AGEs exclusively with ET-1.

However, the present findings cannot prove any causal relationship, since the possibility of contribution of other unknown factors to the association between ET-1 and AGEs should not be overlooked. Furthermore, circulating levels of ET-1 and AGEs do not necessarily reflect the tissue concentrations of these molecules, which determine their direct action on the vasculature.

Overall, our study suggests that PCOS per se may confer an adverse cardiovascular risk profile involving increased circulating AGEs and increased ET-1 
levels. These two proatherogenic molecules are highly likely to interact with each other, since their circulating levels are positively correlated in women with PCOS, independently of obesity, insulin resistance and hyperandrogenemia. Future research should clarify the putative interdependent roles of AGEs and ET-1 and their cardiovascular implications for women with PCOS.

\section{No conflict of interest or financial support declared.}

\section{REFERENCES}

1. Uribarri J, Stirban A, Sander D, et al, 2007 Single oral challenge by advanced glycation end products acutely impairs endothelial function in diabetic and nondiabetic subjects. Diab Care 30: 2579-2582.

2. Stirbanm A, Negrean M, Gotting C, et al, 2008 Dietary advanced glycation endproducts and oxidative stress: in vivo effects on endothelial function and adipokines. Ann NY Acad Sci 1126: 276-279.

3. Tikellis C, Thomas MC, Harcourt BE, et al, 2008 Cardiac inflammation associated with a Western diet is mediated via activation of RAGE by AGEs. Amer J Phys Clin Endocr Metab 295: E323-E330.

4. Chiang KH, Huang PH, Huang SS, Wu TC, Chen JW, Lin SJ 2009 Plasma levels of soluble receptor for advanced glycation end products are associated with endothelial function and predict cardiovascular events in nondiabetic patients. Cor Art Dis 20: 267-273.

5. Semba RD, Bandinelli S, Sun K, Guralnik JM, Ferrucci L 2009 Plasma carboxymethyl-lysine, an advanced glycation end product, and all-cause and cardiovascular disease mortality in older community-dwelling adults. J Amer Ger Soc 57: 1874-1880.

6. Diamanti-Kandarakis E, Piperi C, Kalofoutis A, Creatsas G, 2005 Increased levels of serum advanced glycation end-products in women with polycystic ovary syndrome. Clin Endocr (Oxf) 62: 37-43.

7. Diamanti-Kandarakis E, Katsikis I, Piperi C, et al, 2008 Increased serum advanced glycation end-products is a distinct finding in lean women with polycystic ovary syndrome (PCOS). Clin Endocr (Oxf) 69: 634-641.

8. Shaw LJ, Bairey Merz CN, Azziz R, et al, 2008 Postmenopausal women with a history of irregular menses and elevated androgen measurements at high risk for worsening cardiovascular event-free survival: results from the National Institutes of Health-National Heart, Lung, and Blood Institute sponsored Women's Ischemia Syndrome Evaluation. J Clin Endocr Metab 93: 1276-1284.

9. de Groot PCM, Dekkers OM, Romijn JA, Dieben SWM, Helmerhorst FM, 2011 PCOS, coronary heart disease, stroke and the influence of obesity: a systematic review and meta-analysis. Hum Reprod Update; [Epub ahead of print].
10. Diamanti-Kandarakis E, Spina G, Kouli C, Mygdalis I, 2001 Increased Endothelin-1 Levels in Women with Polycystic Ovary Syndrome and the Beneficial Effect of Metformin Therapy. J Clin Endocr Metab 86: 4666-4673.

11. Diamanti-Kandarakis E, Alexandraki K, Protogerou AP, et al, 2005 Metformin administration improves endothelial function in women with polycystic ovary syndrome. Eur J Endocr 152: 749-756.

12. Orio F Jr, Palomba S, Cascella T, et al, 2004 Early impairment of endothelial structure and function in young normal-weight women with polycystic ovary syndrome. J Clin Endocr Metab 89: 4588-4593.

13. Rajendran S, Willoughby S, Chan WP, et al, 2009 Polycystic ovary syndrome is associated with severe platelet and endothelial dysfunction in both obese and lean subjects. Ather 204: 509-514.

14. Böhm F, Pernow J, 2007 The importance of endothelin-1 for vascular dysfunction in cardiovascular disease. Card Res 76: 8-18.

15. van den Oever I, Raterman HG, Nurmohamed MT, Simsek S, 2010 Endothelial dysfunction, inflammation, and apoptosis in diabetes mellitus. Med Inflam 79: 2393.

16. Zawadzki JK, Dunaif A 1990 Diagnostic criteria for polycystic ovary syndrome: towards a rational approach. In: Dunaif A, Givens JR, Haseltine F, Merriam GR (eds), Polycystic ovary syndrome. Boston: Blackwell Scientific Publications, pp; 377-384.

17. Matthews DR, Hosker JP, Rudenski AS, Naylor BA, Treacher DF, Turner RC, 1985 Homeostasis model assessment: insulin resistance and beta-cell function from fasting plasma glucose and insulin concentrations in man. Diabetes 28: 412-419.

18. Vlassara H, Cai W, Crandall J, et al, 2002 Inflammatory mediators are induced by dietary glycotoxins, a major risk factor for diabetic angiopathy. Proc Nat Acad Sci USA 99: 15596-15601.

19. Fu MX, Wells-Knecht KJ, Blackledge JA, Lyons TJ, Thorpe SR, Baynes JW, 1994 Glycation, glycoxidation, and cross-linking of collagen by glucose. Kinetics, mechanisms, and inhibition of late stages of the Maillard reaction. Diabetes 43: 676-683.

20. Bucala R, Mitchell R, Arnold K, Innerarity T, Vlassara $\mathrm{H}$, Cerami A, 1995 Identification of the major site of apolipoprotein B modification by advanced glycosylation end products blocking uptake by the low density lipoprotein receptor. J Biol Chem 270: 10828-10832.

21. Basta G, Lazzerini G, Massaro M, et al, 2002 Advanced glycation end products activate endothelium through signal-transduction receptor RAGE: a mechanism for amplification of inflammatory responses. Circ 105: 816-822.

22. Schmidt AM, Hori O, Chen JX, et al, 1995 Advanced glycation end products interacting with their endothelial receptor induce expression of vascular cell adhesion molecule-1 (VCAM-1) in cultured human endothelial cells and in mice. A potential mechanism for the acceler- 
ated vasculopathy of diabetes. J Clin Inv 96: 1395-1403.

23. Basta G, 2008 Receptor for advanced glycation endproducts and atherosclerosis: from basic mechanisms to clinical implications. Atherosc 196: 9-21.

24. Diamanti-Kandarakis E, Lambrinoudaki I, Economou F, et al, 2010 Androgens associated with advanced glycation end-products in postmenopausal women. Menop 17: 1182-1187.

25. Quehenberger P, Bierhaus A, Fasching P, et al, 2000 Endothelin 1 transcription is controlled by nuclear factorkappaB in AGE-stimulated cultured endothelial cells. Diabetes 49: 1561-1570.

26. Desai KM, Chang T, Wang H, et al, 2010 Oxidative stress and aging: is methylglyoxal the hidden enemy? Can J Phys Pharm 88: 273-284.

27. Fenkci V, Fenkci S, Yilmazer M, Serteser M, 2003 Decreased total antioxidant status, and increased oxidative stress in women with polycystic ovary syndrome may contribute to the risk of cardiovascular disease. Fertil Steril 80: 123-126.

28. González F, Rote NS, Minium J, Kirwan JP, 2006 Reactive oxygen species-induced oxidative stress in the development of insulin resistance and hyperandrogen- ism in polycystic ovary syndrome. J Clin End Metab 91: 336-340.

29. Victor VM, Rocha M, Bañuls C, et al, 2009 Mitochondrial complex I impairment in leukocytes from polycystic ovary syndrome patients with insulin resistance. J Clin End Metab 94: 3505-3512.

30. Paravicini TM, Touyz RM, 2006 Redox signaling in hypertension. Card Res 71: 247-258.

31. Muniyappa R, Montagnani M, Kon Koh K, Quon M, 2007 Cardiovascular actions of insulin. End Rev 28: 463-491.

32. Riboulet-Chavey A, Pierron A, Durand I, Murdaca J, Giudicelli J, Van Obberghen E, 2006 Methylglyoxal Impairs the Insulin Signaling Pathways Independently of the Formation of Intracellular Reactive Oxygen Species. Diabetes 55: 1289-1299.

33. Polderman KH, Stehouwer CD, van Kamp GJ, Dekker GA, Verheugt FW, Gooren LJ, 1993 Influence of sex hormones on plasma endothelin levels. Ann Int Med 118: 429-432.

34. van Kesteren PJ, Kooistra T, Lansink M, et al, 1998 The effects of sex steroids on plasma levels of marker proteins of endothelial cell functioning. Thromb Haem 79: 1029-1033. 